\title{
The Impact of Sociocultural Changes on the Youth's Achievement Orientation in Fitzgerald's The Beautiful and Damned
}

\author{
S. Itafarida \\ English Department, Faculty of Humanities, Airlangga University, \\ Dharmawangsa Dalam, Surabaya 60286, East Java, Indonesia \\ e-mail: s_itafarida@yahoo.com
}

\begin{abstract}
This essay is an attempt to show Fitzgerald's concern over the fate of the younger generation of the Twenties. Through Anthony's damnation in The Beautiful and Damned he tries to warn the younger generation against the danger of their hedonistic life. The values of hard work, investment, and self-restraint which used to be cherished no longer attract the youth's attention. On the contrary, they actualize their newacquired freedom in parties, in drinking bootleg liquor, in their dancing mania, accompanied by the new rhythm of jazz music symbolizing their freedom.
\end{abstract}

Key words: younger generation, self-restraint, hedonism, penalty

In the first century B.C., Cicero, a Roman orator and spokesman, was worried that "the younger generation was going to the dogs" (Braeman, Bremner, \& Brody, 1968, p. 348), which means that it was heading for its own destruction. Since then, spokesmen for the older generation have frequently been of this opinion. Even today, the same opinion is still heard reiterated all over the world and will surely continue to be heard in the future. The older generation of the Twenties in America was no exception: worrying about the fate of the younger generation yet powerless to do anything. As if paralyzed, the older generation witnessed the younger one destroying itself helplessly. Nothing could be done, except to condemn regretfully, "You are all a lost generation" (Earnest, 1968, p. 259)-a remark made in the presence of Gertrude Stain by a hotel owner in Paris shortly after the end of World War I (Ferrel, 1976, pp. 189-190).

No doubt that every generation rebels to a certain extent against its elders. So did the younger generation of the Twenties. The rebellion of this generation was so remarkable because it caused the break of the old 
culture, the so-called Puritan-republican culture which had dominated America for centuries. Furthermore, this revolt also marked the emergence of the new culture, which was labeled the "culture of abundance" (Susman, 1984, p. xx). The younger generation, learning that the country became

more and more prosperous, realized that they no longer lived in a world of scarcity but in one of abundance, and that they ought to develop new values in keeping with that new status. Consequently, these young people were largely to think of themselves as consumers and were encouraged increasingly not to save but to spend and spend (p. 111). A sin for the previous generations became the thing to do for the so-called "lost generation."

The decade of the Twenties is recognized as a transitional period during which Americans debate "which of their traditional values to preserve or which to modify or abandon" (Martin, J. K., Roberts, R., Mintz, S., McMurry, L. O., \& Jones, J. H., 1989, p. 745). However, living in a time of transition - from the pre-world war I era to the post-world war period - is indeed uneasy. Many Americans, especially the young ones, were "lost" during the period of transition because they were constantly confronted to two opposing values - values already fixed and values that have to be established. Some were repelled by materialism and its delusions. They no longer believed in progress; therefore, they were somehow alienated by the emptiness of business civilization (Blum, J. M., McFeely, W. S., Morgan, E. S., Schlesinger, A. M., Jr., Stampp, K. M., \& Woodward, C. V., 1985, p. 648). Since they only found futility in the past and in the future, they were attempting to create a way of life they liked. They wanted to be free from the authority that they thought had already lost its meaning. What they sought was the pleasures of the present, to live for their private selves and for immediate self-expression.

Further information about this "lost generation" of the Twenties can be obtained through the analysis of literary works, particularly novels. To be sure, there is nothing new about the idea of studying literature as a source of information about culture. Historians have been doing it for a long time. This fact shows that novels provide different dimension from what have been recorded by historians. As a work of art, "literature transcends mere description and objective scientific analysis, penetrating the surfaces of social life, showing the ways in which men and women experience society as feeling" (Laurenson \& Swingewood, 1972, pp. 1213). Therefore, information from novels is expected to complete and enrich 
the writer's understanding of the "lost generation." One such novel is Fitzgerald's The Beautiful and Damned. The novel was chosen because it was written by a representative author of the "lost generation." Moreover, this novel also captured so well the fears and confusion of this generation and its rebellion against the older generation, concealed under the facade of frenetic gaiety.

This novel offers a vivid picture of the undisciplined, fast-paced living of the Roaring Twenties. Furthermore, this book is somehow prophetic in a sense that its author is capable of foreseeing a tragic outcome for the hedonism of the "lost generation" (Hartnett, 1991, p. 67). Anthony Patch, the main character of this novel, is a young aesthete "with the taste and weaknesses of an artist but with no actual creative inspiration" (Eble, 1973, p. 48). He represents a group of Americans, mostly artists and intellectuals, whose lives are torn between two opposing values, the old ones and the new ones. These two antagonistic values are presented in the characters of Adam Patch, Anthony's grandfather, and Gloria Gilbert, Anthony's wife, respectively. Throughout the novel Fitzgerald depicted Anthony's confusion to cope with the two sets of values in which he was trapped.

The primary objective of this study is to evaluate the impact of the transformation of values in America in the Twenties on the younger generation of that period. Furthermore, this study is also intended to interpret Fitzgerald's vision of his own generation, which is later to be dubbed the "lost generation." To achieve that goal, the conflicting old and new values will be discussed in order to get some ideas of how far this antagonistic values cause conflict in the life of Anthony Patch, the protagonist of this novel.

\section{METHOD}

One of the purposes of this study is to find out the significance of the so-called "lost generation" in the development of American culture through the analysis of written and particularly literary evidence. In American Studies discipline, the novel, the artwork, which will be analyzed here, is viewed as a piece of documentary evidence. This in turn is used - adopting a method of inquiry commonly used by historians - as a means to reconstruct an age and a culture because the work itself is considered primarily as an expression of the culture's 'zeitgeist' (Grebstein, 1968, p. 7). Furthermore, Americanists regard literary works as a source of information 
about culture since it is assumed that the manifest content of literature reflects important characteristics of culture (Kwiat \& Turpie, 1960, p. 87).

Walker (1958), in his essay "American Civ. at Raymond," declares that American Studies begins with the microcosm, not the macrocosm. Whether looking at political stump speech, a public building, a historical event, a poet, the strategy practiced is to ask questions of it so that these pieces nay be viewed, conceived, in their functioning cultural context. "Start small, and move outward." It is assumed that by delving deeply into particularity, the general significance may in time come to be revealed (p. 474). Therefore, starting from a piece of literary work, The Beautiful and Damned, an individual creation, the significance of the phenomenon of the "lost generation" is expected to be revealed.

Gordon Kelly, one of the prominent Americanists, even insists that "imaginative literature, great or not, must be treated as any other human product - "as a particular construction of reality coming from a particular context, created and consumed by particular types of people in response to particular experiences in their world." Hence Kelly declares that "literature must be deeply grounded in social reality before it can be understood culturally" (Wise, 1979, p. 321).

Thus, in order to have a better interpretation of Fitzgerald's novel, a sociocultural approach will be applied to the novel. This approach mainly concerns with the literary work's interaction with life, which involves not only the work's social, economic, and political implications but also its moral and cultural implications (Grebstein, 1968, p. 162).

In his introduction to "The Sociocultural Critic", Grebstein (1968) indicates that in the eyes of a sociocultural critic, every literary work is regarded as "the result of a complex interaction of social and cultural factors" and the work of art itself as "a complex cultural object." Therefore, "the literary work cannot be fully or truly understood apart from the milieu or culture or civilization in which it was produced." It means that literature must be studied in the widest possible context rather than by itself. He points out further that "any literary work that endures is profoundly moral, both in its relation to the culture in which it appears and to the individual reader." It is moral in the sense that it supports a particular code or system of behavior and that it is engrossed in life and presents an evaluative response to life (pp. 164-165). 


\section{FINDINGS AND DISCUSSION}

Success can mean many things. It is often associated with money, wealth, fame, achievement, good life, and others. In The Beautiful and Damned Fitzgerald relates the American Dream of success to the idea of wealth. He delineates clearly the effect of wealth on Anthony's life and how wealth itself becomes destructive and ruins his life.

Being the only grandson of a multimillionaire has inevitably made Anthony dream that some golden day he will inherit most of his grandfather's money. The dream has already filled his mind early in his life and has developed along with his growth that it becomes a kind of obsession in him. It appears again and again in his conversation with his wife, Gloria.

I think we ought to travel a lot. I want to go to Mediterranean and Italy... And then some time when we have more money we'll build a magnificent estate, won't we? Oh, yes, with private swimming pools. Dozens of them. And private rivers. Oh, I wish it were now. (Fitzgerald, 1922, p. 137)

Unfortunately, Anthony's good life and the prospect of a great inheritance have apparently paralyzed him, in a sense that they have caused him to lose his motivation to work.

In the Twenties, the time of Anthony's life, "It is estimated that a person earning $\$ 6,000$ or more a year was in a select income group, approximately the upper five percent of the population" (Bogart, 1969, pp. 4-5). Anthony's income is about seven thousand a year, the interest of money inherited from his mother. With that amount of money young Anthony, living after the mode of the true man of leisure, can get whatever he wants - good apartment, expensive clothing, good food, and other forms of enjoyment. Like other youths of his time Anthony is full of disillusionment. He thinks that money can buy everything, thus guarantee his happiness. Schlereth (1992) also confirmed that in that period "new institutions of commercial leisure-amusement parks, vaudeville, and spectator sports - suggested that fun could be bought like anything else" ( $p$. 141).

Anthony's good life - which symbolizes the prosperity of the decade - has made him think that he does not need to commit himself to 
work. "I do nothing, for there's nothing I can do that's worth doing" (Fitzgerald, 1922, p. 65). Obviously young Anthony believes in the futility of effort; that is why he does not understand "why people think that every young man ought to go down-town and work ten hours a day for the best twenty years of his life at dull, unimaginative work, certainly not altruistic work" (p. 65). Without working Anthony has been able to live above average, that is why the idea of work is apparently out of his mind.

Actually, Anthony's conviction of the futility of effort, of the wisdom of abnegation has only started in his early Twenties. This conviction has been confirmed by the philosophies he has admired as well as by his association with Maury Noble, and later with his wife, Gloria (p. 284). This fact indicates that Anthony's conviction of the futility of effort is also shared by his contemporaries. As an intellectual person Anthony must have read Herbert Spencer, a philosopher that he comes to admire. Durant mentions in The Story of Philosophy that there is in Spencer "a sense of the futility of human effort." He explains further that "At the end of his triumphant career he (Spencer) expressed his feeling that life was not worth living" (p. 369). Apparently, Anthony and his contemporaries merely adopt this philosophy to justify their pleasure-seeking lives.

In fact, Cowley (1984), the chronicler of the Twenties, also notices that the younger generation of the period "had grown up in the years when middle-class Americans read Herbert Spencer and believed in the doctrine of automatic social evolution" (p. 26). Consequently, young men and women of Fitzgerald's time believe that "the world would improve without their help" (p. 26). In a way, this serves as a kind of excuse for their careless way of life.

During the decade urban life becomes more and more fascinating, especially for young people, that living in the city becomes their dream. The growth of the city has also tempted the newly married couple, Anthony and Gloria, to come in search of happiness together. Just like other members of the young generation of the time, they regard New York as "the city of luxury and mystery, of preposterous hopes and exotic dreams" (Fitzgerald, 1922, p. 282). As a big city, New York is certainly the place where the American dream is exposed daily through the media and the way of life of its rich inhabitants. Moreover, New York also offers its inhabitants so many opportunities for amusements such as nightclubs, speakeasies, movies, and theatres. Therefore, like those who settle in big cities, Anthony and Gloria are tempted to conform to an urban standard 
and way of living. The glamorous life around them has unavoidably poisoned their mind in such a way that they bitterly determine to live as they do, believing that their dream will come true.

The trouble is that Anthony and his wife take leisure almost as a way of life. They spend most of their time to enjoy life fully, drifting from one place to another, going to parties and getting drunk with their friends almost every night, and enjoy other forms of entertainments.

...they had loitered, restive and lazily extravagant, along the California coast, joining other parties intermittently and drifting from Pasadena to Coronado, from Coronado to Santa Barbara, with no purpose more apparent than Gloria's desire to dance by different music... (p. 191)

They simply live for now because they do not believe in the future. For them "This is life! Who cares for the morrow?" (p. 70). That is why they neglect work at all. What they seek is the pleasure of the present, to live for their private selves and for immediate self-expression. Actually Anthony has realized that "He had been futile in longing to drift and dream; no one drifted except to maelstroms, no one dreamed, without his dreams becoming fantastic nightmares of indecision and regret" (p. 282). Nevertheless, Antony and Gloria have decided "Not to be sorry, not to lose one cry of regret, to live according to a clear code of honor toward each other, and to seek the moment's happiness as fervently and persistently as possible [sic]" (p. 226). This deviant attitude seems to be common among the youth in the period of transition.

The great development of mass media such as magazines, television, radio, movies and advertisements has made the American dreams rise beyond the bounds of reality. Through these media the clichés of the American good life are bombarded. Advertisements of various products increasingly confuse many young people of what they are actually after in their life. Success is ten interpreted in different ways. Car, for example, which is very popular at that time, not only offers faster transportation but also status. More than that, it also gives the image of being successful. That is why Anthony and Gloria decide to buy a new car. The ideas of having a car has already excited them and made them forget momentarily about their problems. They do not care if their new roadster only provides them with instant satisfaction for it is the pleasure of the moment that they really seek. 
It is also indicated that the development of moving picture industry in America has influenced young people of that time. "In addition to their popular entertainment appeal, movies exerted a tremendous influence in shaping the values and attitudes of the American people" (Bogart, 1969, p. 10). "I want to be a successful sensation in the movies," Gloria announces. "I hear that Mary Pickford makes a million dollars annually" (Fitzgerald, 1922, p. 213). Mary Pickford is one of the silent screen leading figures in the Twenties. Apparently, due to the growth of moving picture industry, many young people are interested to become movie stars which is relatively a new profession at that time. Certainly it is the glamour and excitement of that celebrity - a person who becomes famous through the mass media - that they seek because it offers admiration and envy.

The widespread distribution of mass media has made celebrities very popular among the American society. They often become interesting subjects of discussion, and even models - especially for the youths. The popularity of these celebrities is generally regarded as a symbol of success. "Accordingly," says Lasch (1979), "it is evanescent, like news itself, which loses its interest when it loses its novelty" (p. 117). Nevertheless, people dream to be admired and envied like those celebrities.

The idea of becoming an actress appeals to Gloria very much but Anthony objects to her intention.

"But it's so silly! You don't want to go into the movies - moon around a studio all day with a lot of cheap chorus people..."

"Well, I can't see how you'd object to my trying."

"I do though. I hate actors."

"Oh, you make me tired. Do you imagine I brave a very thrilling tine dozing on this damn porch?"

"You wouldn't mind if you loved me." (Fitzgerald, 1922, p. 214)

Apparently Anthony still believes in the old values, especially those concerning women's role in society. That is why he objects to the idea of Gloria becoming an actress. He seems to think that just being in love is enough for a woman. Thus he expects Gloria to stay at home and make herself pretty when he comes home.

The younger generation of the Twenties no longer believes that success can be achieved only by starting very low. From the beginning Anthony has considered himself to be the elect; hence, he considers that 
"he would one day accomplish some quite subtle tubing that the elect would deem worthy..." (p. 3). Apparently, Anthony dreams to be a booster, an up lifter, which is experienced by some lucky Americans at that time, including his grandfather. He wants to strike himself rich without having to work hard. That is why Anthony always wishes his grandfather to die so as to grab his fortune. It seems that through Anthony's intention to leave work at all to achieve his goal Fitzgerald wants to show one among other signs of the decline of the American dream of upward mobility.

The fact that Anthony is disinherited forces him to face the reality of his life. So far he has accustomed to enjoying a life of leisure, therefore, even though he realizes that things have changed, it is very difficult for him to accept the reality that he has to commit himself to work.

In the early days of his marriage with Gloria "seventy-five bundled a year bad seemed ample for a young couple, especially when augmented by the expectation of many millions" (p. 390). Now that the value of the dollar decreases, the same amount of money they receive has less purchasing power. Therefore, living within their income has become impossible. Meanwhile, Anthony counts that their capital will last for about another seven years, if they keep loafing. Moreover, the payment of their lawyer's retaining fee of fifteen thousand dollars shows the fact that their bankruptcy is startlingly obvious.

The promise of money inherited from his grandfather has spoiled Anthony in such a way that to think of starting from "wreck" is a horror for him.

Here I am, thirty-two. Suppose I did start at some idiotic business. Perhaps in two years I might rise to fifty dollars a week-with luck. That's if I could get a job at all; there's an awful lot of unemployment. Well, suppose I made fifty a week. Do you think I'd be any happier? Do you think that if I don't get this money of my grandfather's life will be endurable? (p. 408)

Nevertheless, Anthony attempts to become a salesman. In the Twenties salesmanship becomes increasingly important because of the changes in the structure of society: the sifting emphasis from capitalist production to consumption. Being a successful salesman needs personal magnetism, a quality which supposedly enables a man to influence and dominate others. Unfortunately Anthony lacks this quality, thus his attempt to succeed in this field is wrong. 
Failing in achieving success as a salesman, Anthony joins the army. Just like his contemporaries, Anthony sees war as something glorious. For that reason he wants to seek fame as a war hero. Anthony's contingent happens to be sent to the Southern Camp, meaning that he has to leave Gloria alone in New York. This really is something for Anthony because since their marriage he never stays away from his wife for more than a night. He finds this as a kind of freedom, a freedom from his dependency on her.

Anthony's weakness and dependency on women is also shown through his relationship with Dorothy Raycroft, an innocent girl from a poorer background. Anthony finds in her a new excitement and stimulus which enable him to regain his self-confidence. Once again be believes that he is still admired. Anthony feels he is somebody in front of her. Anthony's affairs with Dorothy Raycroff are actually an inevitable result of his increasing carelessness about himself. He lacks the ability to decide what is good for him.

He did not go to her desiring to posses the desirable, nor did he fall before a personality more vital, more compelling than his own, as he had done with Gloria four years before. He merely slid into the matter through his inability to make definite judgments. (pp. 324-325)

Antony dreams to succeed in the army but his affair with Dorothy has ruined his dream. He often breaks the military discipline in order to meet her. Finally, he is caught by a military policeman and his rank is reduced without trial. Again this incident shows his carelessness in achieving his goal, if he has one at all. Obviously, this phenomenal carelessness marks the decline of the American dream of individual achievement.

\section{CONCLUSION}

The Beautiful and Damned which was written in the early twenties is a reflection of the undisciplined, irresponsible, fast-paced living of the younger generation of the period. The novel, with its inclination for the portrayal of material reality and with its sensitivity to social experience, proves to be important literary evidence for Americanists as well as for historians to reconstruct the confusing decade of the Twenties, which is known as the "Roaring Twenties", the "Fabulous Twenties", and more 
popularly the "Jazz Age". Though this period superficially appears as a time of peace and prosperity, the reality beneath seems to be quite contradictory. Through some literary evidence published during that period, it can be seen that the decade of the Twenties is in fact marked by sharp contrasts between: certainty and insecurity, stability and confusion, content and discontent, and conformity and rebellion.

The rapid social change taking place at that time has caused the emergence of a generation gap between the pre-war and post-war generations. The pre-war generation which is still strongly attached to the Victorian tradition and manner of living lives in a period of inhibitions. Hence, those of the pre-war period are basically moral in both their ideas and actions. On the contrary, the younger generation, spoiled by the prosperity of the post-war period, seems to be quite loose in their manners and moral, when they are judged by standards retained from the earlier time. As a consequence, these two world views, reflecting fundamentally different visions of society and self, are moving into conflict in America of the 1920s.

F. Scott Fitzgerald, the writer of this novel, becomes mature exactly in that period of transition. This maturity seems to give him wisdom to evaluate what he continually observes in his life time and to give it something of a judgment. As a sensitive observer who himself is engrossed in the life of that period, Fitzgerald obviously has a thorough grasp of his observed material and feels compelled to convey as much of the meaning of experience as possible. Thus, in the midst of the prevailing confusion and uncertainty, Fitzgerald, the moralist, attempts to preach at the younger generation through this novel.

Antony Patch, the protagonist of the novel, is portrayed as a representative of the generation of artists and intellectuals who are dissatisfied with the repressive condition in America. His European education and adventure apparently dictates him to make an absolute break with the standards of the pre-war generation, but his Puritan conscience, which has shaped his imagination and his vision of reality, occasionally disturbs his pleasure-seeking adventure. Finally, Antony's inability to cope with reality and experience has shaken his psychological balance. He is penalized for the mistakes he has committed in his life.

Through Anthony's damnation Fitzgerald tries to warn the younger generation against the danger of their hedonistic life. Apparently be believes in the power of this novel to communicate his concern over the 
fate of the younger generation. As the author becomes more mature, he no longer advocates the pleasure-seeking morality of the youth that he has himself set in his previous novel This Side of Paradise, because he has been able to prophesy its tragic outcome. His maturity itself comes with his awareness of the dangers of the irresponsible youthful life. That is why he feels responsible to save the younger generation from the coming damnation.

Apparently Fitzgerald has a negative view over American women of the period. He even equates them with leeches that suck everything out of their man and leave them impotent. No wonder that be blames the beautiful Gloria for the "damnation" of her own life and that of her husband Anthony. Nevertheless, there is a feeling in Fitzgerald's works that the author himself admits women's superiority over men. Gloria Gilbert and Daisy Fay, then known as flappers - free-spirited women who love lifewho become the dominating symbol of the Twenties, are fine examples of this type of women, beautiful, independent, irresponsible, and men-suckers. Throughout the novel Fitzgerald seems to suggest that beauty serves as a magic wand for women to take everything they like from life.

As the "prophet" of the Jazz Age Fitzgerald not only condemns his generation but also provides it with a way out. Despite his personal doubt, the writer suggests that work is the only salvation for the young people to avoid damnation. Even though they work simply to forget that there is nothing worthwhile to work for, they must work. The activity is expected to occupy much of their time and energy so as not to give then any opportunity to loaf about.

Anthony's determination to reject his grandfather's continuous advice, his reluctance to visit his house and to communicate with him, refer to the existence of a gulf between the old and the young. As a responsive author Fitzgerald seemingly realizes that something wrong has happened between the old and the young. As a spokesman of the younger generation the writer tries to call out his disagreement on the elder's treatment of the youth. In one of his interviews the writer suggests that "the less parents of today try to tell their children the more effective they can be in making them believe in a few old truths." This undoubtedly reflects some basic values to be respected in American society, namely individualism, independence and freedom.

What can be inferred from the whole discussion is that starting from Fitzgerald's novel, an individual creation, which serves as a piece of 
documentary evidence contemporary to the period under study, the significance of the phenomenon of the so-called "lost generation" can be revealed. It is in fact a kind of cultural movement which emerges out of the condition of the age. Its existence is somehow inevitable for it serves as the youths' responds on the rapid socio-cultural changes that happen after World War I.

In an age of global information, learning about other culture is not only very important but is also a must. In this case American culture is especially important because it belongs to the world superpower, which is assumed to set forth the standards of manners and moral for the youth all over the world. Its influence to Indonesian youths is certainly undebatable. Through television screens it can be observed that American and Indonesian youths are sharing the same attitude, facing the same problems, acting the same way, not to mention wearing the same fashion for it is too obvious to be unnoticed. It is therefore imperative for Indonesian government to anticipate the impact of global information on the youths so as to prevent them from its negative influences.

\section{REFERENCES}

Blum, J. M., McFeely, W. S., Morgan, E. S., Schlesinger, A. M., Jr., Stampp, K. M., \& Woodward, C. V. (Eds.). (1985). The national experience (Part 2). San Diego: Harcourt.

Bogart, M. (Ed.). (1969). The jazz age. New York: Scribner's.

Braemen, J., Bremner, R. H., \& Brody, D. (Eds.). (1968). Change and continuity in twentieth century America: The 1920's Ohio: Ohio State University Press.

Cowley, M. (1984). A second flowering: Works and days of the lost generation. New York: Viking-Penguin.

Earnest, E. (1968). Expatriates and patriots. North Carolina: Duke University Press.

Eble, K. (Ed.). (1973). F. Scott Fitzgerald: A collection of criticism. New York: McGraw Hill.

Ferrel, S. (1976). Lost generation. In L. B. Kets (Ed.), Dictionary of American history IV. New York: Scribner's.

Fitzgerald, F. S. (1922). The beautiful and damned. New York: Scribner's. 
Grebstein, S. N. (Ed.). (1968). Perspectives in contemporary criticism. New York: Harper.

Hartnett, K. S. (1991). Zelda Fitzgerald and the failure of the American dream for women. New York: Peter Long.

Kwiat, J. J., \& Turpie, M. C. (1960). Studies in American culture: Dominant ideas and images. Minnesota: University of Minnesota Press.

Lasch, C. (1979). The culture of narcissism: American life in an age of diminishing expectations. New York: Norton.

Laurenson, D., \& Swingwood, A. (1972). The sociology of literature. London: Paladin.

Martin, J. K., Roberts, R., Mintz, S., McMurry, L. O., \& Jones, J. H. (1989). America and its people. New York: Harper-Collins.

Schlereth, T. J. (1992). Victorian America: Transformations in everyday lilfe, 1876-1915. New York: Harper Perennial.

Susman, W. I. (1984). Culture as history: The transformation of American society in the 20th century. New York: Pantheon.

Walker, R. (1958). American studies in the United States: A survey of college programs. Louisiana: Louisiana State.

Wise, G. (1979). Paradigm dramas' in American studies: A cultural and institutional history of the movement. American Quarterly, 293-336. 